\title{
Clinical and Sociodemographic Profile of the First 33 COVID 19 Cases Treated at Dedicated Treatment Center in Ethiopia.
}

Sisay Teklu Waji ( $\sim$ samitedi1@gmail.com )

Addis Ababa University, College of Health Sciences, School of Medicine

Menbeu Sultan

Saint Paul's Hospital Millennium Medical College

Aklilu Azazh Azazh

Addis Ababa University College of Health Sciences

Aschalew Worku

Addis Ababa University College of Health Sciences

Berhane Redae

Jhpiego Ethiopia

Miraf Walelign

$\mathrm{FMOH}$

\section{Muluwork Tefera}

Addis Ababa University College of Health Sciences

\section{Rahel Argaw}

Addis Ababa University College of Health Sciences

Woldesenbet Waganew

Saint Paul's Hospital Millennium Medical College

Sisay Yifru

$\mathrm{FMOH}$

\section{Wondwossen Amogne}

Addis Ababa University College of Health Sciences

\section{Natnael Tessema}

Save the Children Ethiopia

Abebaw Bekele

Ekka-Kotebe Hospital

Yonas Gebreegziabher

Ekka-Kotebe Hospital

\section{Hiruy Araya}

Ekka-Kotebe Hospital

\section{Addisu Birhanu}


Ekka-Kotebe Hospital

Getachew Demoz

Ekka-Kotebe Hospital

\section{Bethelehem Tadesse}

Ekka-kotebe Hospital

\section{Yakob Seman}

$\mathrm{FMOH}$

\section{Abebe Genetu}

Amauer Hansen Research Institute

Aschalew Abayneh

Ethiopian Public Health Institute

\section{Research article}

Keywords: COVID 19, SARS CoV2, Pandemic, Ekka-Kotebe, Ethiopia

Posted Date: May 20th, 2020

DOI: https://doi.org/10.21203/rs.3.rs-27800/v1

License: (c) (1) This work is licensed under a Creative Commons Attribution 4.0 International License. Read Full License 


\section{Abstract}

Back ground: Severe respiratory tract infection caused by family of Corona viruses has become world pandemic and is claiming many lives. In this study we have described the first 33 cases diagnosed, admitted and treated in Ethiopia COVID treatment center with the aim of contributing some information to the local and global effort of controlling the pandemic.

Method: Descriptive study was conducted on the first 33 consecutive RT-PCR confirmed COVID 19 cases diagnosed and managed at Ekka-Kotebe COVID treatment center in Addis Ababa, Ethiopia.

Result: Data of the first 33 COVID 19 confirmed patients treated at Ekka-kotebe COVID treatment center was analyzed. The median age of the cases was 36 years. Cough, headache and fever were the most frequent symptoms in the firs 33 COVID 19 cases reported in this study. Diarrhea, sore throats, loss of taste and/or smell sensation were among the rare symptoms. Most (84.8\%) had mild to moderate disease and $15.2 \%(n=5)$ were critical at the time of admission. Among the five ICU admissions, four patients required invasive mechanical ventilation. Both mild and moderate cases were managed in the general ward with or without low flow oxygen treatment. Thirty cases were discharged after two pairs of nasopharyngeal and oropharyngeal samples turned negative for SARS CoV2. Three cases from the ICU died while on mechanical ventilator. Age of the two deaths was 65 years and one was 60 years. With the exception of three, all cases were either imported from abroad or had contact with confirmed case.

\section{Background}

Pneumonia of unknown cause detected in Wuhan China was first reported to the WHO country office on December 31/2019. The outbreak was declared a Public Health Emergency of International Concern on January 30/2020. World Health Organization (WHO) used the term COVID 19 to refer to acute respiratory infection caused by family of corona virus initially seen in Wuhan, China (1). Currently the virus that causes COVID 19 is referred as severe acute respiratory syndrome corona virus 2 (SARS CoV2), by the International Committee on Taxonomy of Viruses (2).

The report of WHO-China joint Mission, deployed to assess the outbreak of respiratory infection of unknown etiology found that COVID 19 is a zoonotic disease. Viral Bioinformatics analyses indicated that the virus had features typical of the coronavirus family belonging to the Beta coronavirus $2 \mathrm{~B}$ lineage. In this report, median age of affected people was 51 years and the report revealed that the virus is transmitted via droplets and fomites (3). On March 11/2020 the WHO director general declared that COVID 19 is global pandemic (4).

The recent COVID 19 pandemic is one of the rapidly spreading infectious disease epidemics the world has witnessed. Initially seen as a single case in Hubie province, Wuhan city in China, it has reached all countries in the world with in three months (5). Like the infectious epidemics in the past it followed the tourist and business routs to cross borders and reach almost all countries. Up to April 26/2020, nearly 3 million confirmed cases and 206,000 deaths were reported throughout the world (6). The spread of the 
disease and the damage it is causing vary from country to country. Early introduction of preventive public health measures proved to reduce the burden of the disease and fatality.

There are limited reports on this new disease and the available reports are mostly from China where the outbreak was initially reported and most are case series. Like other respiratory tract infections, hand hygiene, protecting the nose and face by face mask are believed to protect transmission. But recent reports revealed virus is detectable in the GI secretions. The incubation period varies from 2 to 14 days. The virus has been isolated from respiratory secretions prior to development of symptoms in presymptomatic patients, making prevention of transmission very difficult. Clinical manifestations vary from asymptomatic (pre symptomatic) to respiratory failure (7).

A report on 1099 confirmed COVID 19 cases from 552 hospitals in 30 different regions of mainland China showed that the most common symptoms were fever (43.8\% on admission, and $88.7 \%$ during hospitalization) and cough (67.8\%) and diarrhea (3.8\%). Most cases were mild and severe disease reported in elderly and in those with comorbidity with 15 reported deaths (8).

Another study from India showed most laboratory confirmed cases were male, symptomatic, had travel history out of India. Majority were young, twenty-nine percent of patients had comorbidities and most recovered from the disease. The common symptoms observed were fever and cough (9). Next to China, Italy has become the epicenter for COVID in Europe (10).

A retrospective study done in 1591 intensive care unit (ICU) admitted cases in Lombardy, Italy showed that the majority of cases are old with median age of 63 years. The majority of patients needed respiratory support whereas $88 \%(n=1150)$ needed invasive mechanical ventilation and $26 \%(n=405)$ of cases died (11).

\section{Methods}

This study is an observational descriptive study on 33 COVID 19 RT-PCR confirmed cases admitted to and managed at Ekka-Kotebe COVID 19 treatment center. The cases in this study include all cases that had an outcome until April 20/2020, including the first case ever diagnosed in Ethiopia on March 13, more than two months after the first case reported in Wuhan China. The study describes the socio-demography, clinical presentation and treatment outcome of the cases. Data was collected from patient treatment chart, interview of patients for missing data and analyzed using EPI Info version 25.

Ethiopian Federal government started to mobilize all governmental bodies and started readiness for the epidemics since the report of the first case in China. The Federal Ministry of Health and Ethiopian Public Health Institute (EPHI) were given full authority in preventing, testing, reporting and treating COVID 19 in Ethiopia. The initial measures taken were screening all arrivals from COVID 19 affected countries at Bole international airport for the presence of fever, collect their address and check for the development of any COVID symptoms for two weeks by telephone. The first case was diagnosed on March 13, three days after he arrived from Burkina Faso. All his contacts were traced and quarantined. Contact tracing and 
quarantine, isolation of patients with COVID 19 symptoms visiting health facilities were started at the same time.

National preparedness plan introduced in the country includes alerting all the regions about the epidemics, educating the people on social distancing, hand hygiene, avoiding mass gathering at the market places, social events and religious places.

The mass media focused on health education and expert advices on most television and audio channels introduced. Frequent free text messages about COVID and COVID 19 alerting voice messages during all telephone calls was put in place by telephone service provider throughout the country. Hand washing at public places like bus and train stations, at the gate of banks and supermarkets was introduced starting from early March.

All suspected cases and those with contact with confirmed cases were tested using RT PCR initially at the EPHI laboratory but subsequently more laboratories were opened and the number of tests done every day increased. Sample collection, transport and testing followed standard COVID 19 sample collection, transport and testing techniques recommended by WHO.

RT-PCR confirmed COVID 19 cases are triaged at the triage area at the Ekka-Kotebe treatment center according to the national triage criteria. Mild and moderate cases are admitted to the general ward, severe cases to severe cases ward and critical cases to the ICU. All cases were treated with chloroquine sulphate $500 \mathrm{mg}$ PO BID for five days and Azithromycin $500 \mathrm{mg} \mathrm{PO/} \mathrm{day} \mathrm{for} \mathrm{three} \mathrm{days.} \mathrm{Oxygen} \mathrm{therapy} \mathrm{was}$

provided based on the oxygen saturation and respiratory condition of the patient. Intravenous Ceftriaxone was given for all moderate, severe and critical cases. Fever and headache was managed with paracetamol (acetaminophen) $1 \mathrm{gm}$ PO every 6 hours as required. Discharge criteria used in the center is complete resolution of symptoms and negative RT-PCR on two pairs of nasopharyngeal and oropharyngeal samples taken 24 hours apart.

\section{Result}

This is a report of the first 33 COVID 19 patients in Ethiopia. The median age of the cases included in this study was 36 years ( 11 months to 84 years) with IQR of 22 years. The average length of hospitalization was 14 days ( 9 to 21 days). As shown on Table 1, majority of the patients $24 / 33$ (73\%) were males and $85 \%(n=28)$ were Ethiopians. Twenty-four patients $(73 \%)$ had travel history to a country with confirmed COVID 19 cases, 6 (18\%) had contact with COVID 19 confirmed patient in Ethiopia with no travel history abroad. In three cases there was neither travel history nor contact with COVID confirmed case. Seventyfive percent of the patients $(n=25)$ had mild illness at the time of admission. Five patients were admitted to intensive care units and four of them were mechanically ventilated. Three patients on mechanical ventilator in the ICU died, possible cause of death being sever hypoxia secondary to ARDS. Medical comorbidities were identified in $15 \%(n=5)$ of cases included in this study. One case of COPD and another case of essential hypertension had mild COVID 19, both recovered. Two of the three deaths had diabetes and one had hypertension. Duration of intensive care unit stay ranges from 3 to 8 days. Those 
patients who died in the ICU stayed for an average of five days in the hospital. The oldest patient among the 33 cases in this report was 84 years old critical COVID with no comorbidity, was admitted to the ICU, discharged after full recovery. 
Table 1

Socio-demographic characteristics of the first 33 COVID 19 patients admitted at Ekka-Kotebe Hospital, Addis Ababa,

Ethiopia.

\begin{tabular}{|c|c|c|c|}
\hline \multicolumn{2}{|l|}{ Characteristics } & $\begin{array}{l}\text { Number } \\
\mathrm{N}=\mathbf{3 3}\end{array}$ & $\begin{array}{l}\text { Percent } \\
100 \%\end{array}$ \\
\hline \multirow{7}{*}{ Age, years } & & & \\
\hline & $<20$ & 2 & 6.1 \\
\hline & 21 to 30 & 8 & 42.2 \\
\hline & 31 to 40 & 9 & 27.3 \\
\hline & 41 to 50 & 8 & 24.2 \\
\hline & 51 to 60 & 1 & 3.0 \\
\hline & 61 and above & 5 & 15.2 \\
\hline \multirow[t]{2}{*}{ Gender } & Male & 24 & 72.7 \\
\hline & Female & 9 & 27.3 \\
\hline \multirow[t]{4}{*}{ Nationalities } & Ethiopian & 28 & 84.8 \\
\hline & Japanese & 3 & 9 \\
\hline & Australia & 1 & 3 \\
\hline & Mauritius & 1 & 3 \\
\hline \multirow[t]{11}{*}{ Occupation } & Business man & 14 & 48.3 \\
\hline & House wife & 3 & 10.3 \\
\hline & Cabin crew & 1 & 3.4 \\
\hline & Diplomat & 1 & 3.4 \\
\hline & Pharmacist & 2 & $7 / 0$ \\
\hline & Nurse & 2 & 7.0 \\
\hline & Security guard & 1 & 3.4 \\
\hline & Student & 1 & 3.4 \\
\hline & lawyer & 1 & 3.4 \\
\hline & Unemployed & 1 & 3.4 \\
\hline & Driver & 2 & 6.9 \\
\hline \multirow[t]{2}{*}{ Travel History to } & No travel history & 9 & 27.3 \\
\hline & Dubai & 12 & 36.4 \\
\hline
\end{tabular}




\begin{tabular}{|c|c|c|c|}
\hline \multicolumn{2}{|l|}{ Characteristics } & $\begin{array}{l}\text { Number } \\
\mathrm{N}=\mathbf{3 3}\end{array}$ & $\begin{array}{l}\text { Percen } \\
100 \%\end{array}$ \\
\hline & Belgium & 1 & 3.0 \\
\hline & Burkina Faso & 1 & 3.0 \\
\hline & Congo Brazzaville & 2 & 6.0 \\
\hline & London & 1 & 3.0 \\
\hline & France & 1 & 3.0 \\
\hline & Japan & 1 & 3.0 \\
\hline & Canada & 1 & 3.0 \\
\hline & Kenya & 1 & 3.0 \\
\hline & Swaziland & 1 & 3.0 \\
\hline & Thailand & 1 & 3.0 \\
\hline & USA & 1 & 3.0 \\
\hline \multirow[t]{8}{*}{ Comorbidity } & No comorbidity & 28 & 84.8 \\
\hline & HTN & 2 & 6.1 \\
\hline & $\mathrm{DM}$ & 2 & 6.1 \\
\hline & COPD & 1 & 3.0 \\
\hline & Mild & 25 & 75.8 \\
\hline & Moderate & 3 & 9.1 \\
\hline & Severe & 0 & $0 \%$ \\
\hline & Critical & 5 & $15.1 \%$ \\
\hline
\end{tabular}

As shown on table 2 , the presenting symptoms in $70 \%$ of the patients was cough while nearly half of the patients had fever before or at the time of presentation to the hospital and another half of the patient had headache. Diarrhea in $6(18 \%)$, sore throats in $5(15 \%)$ and dysuria in $2(6 \%)$ were among the rare symptoms in this study. Loss of taste and/or smell sensation was reported in $4(12 \%)$ patients. On laboratory investigations, 18 patients $(54.5 \%)$ had lymphopenia, $10 / 23(43.4 \%)$ of them had raised creatinine and more than two third of the patients had raised AST and ALP.

Chest X-ray was performed for ten patients, 6 was reported normal, 2 patients had bilateral pleural effusion and additional 2 patients had bilateral diffuse infiltration. The 84 years old patient had chest CT with evidence of ARDS. 
Table 2

Major presenting symptoms of the first 33 COVID 19 patients admitted at Ekka-Kotebe Hospital, Addis Ababa, Ethiopia.

\begin{tabular}{|lll|}
\hline Characterstics & Number & Percent \\
\hline Fever & $\mathbf{N 3 3}$ & $\mathbf{1 0 0 \%}$ \\
\hline Cough & 16 & 48.5 \\
\hline Myalgia & 23 & 70 \\
\hline SOB & 15 & 45.5 \\
\hline Diarrhea & 5 & 15 \\
\hline Sour throat & 6 & 18.2 \\
\hline Headache & 5 & 15.2 \\
\hline Fatigue & 17 & 51.5 \\
\hline Dysuria & 3 & 9 \\
\hline Loss of taste and/or smell sensation & 4 & 12 \\
\hline
\end{tabular}


Table 3

Laboratory results of the first 33 COVID 19 patients admitted at Ekka-Kotebe Hospital, Addis Ababa,

Ethiopia.

\begin{tabular}{|c|c|c|c|}
\hline \multicolumn{2}{|l|}{ Characteristics } & Number & $\begin{array}{l}\text { Percent } \\
100 \%\end{array}$ \\
\hline \multirow[t]{3}{*}{ Leucocyte count } & High & 1 & 3.0 \\
\hline & Low & 12 & 36.4 \\
\hline & Normal & 20 & 60.6 \\
\hline \multirow[t]{3}{*}{ Lymphocyte count } & High & 3 & 9.1 \\
\hline & Low & 18 & 54.5 \\
\hline & Normal & 12 & 36.4 \\
\hline \multirow[t]{2}{*}{ Platelet count } & Low & 3 & 9.4 \\
\hline & Normal & 29 & 90.6 \\
\hline \multirow[t]{2}{*}{ Creatinine } & High & 10 & 43.5 \\
\hline & Normal & 13 & 56.5 \\
\hline \multirow[t]{2}{*}{ AST } & High & 7 & 46.7 \\
\hline & Normal & 8 & 53.3 \\
\hline \multirow[t]{2}{*}{ ALT } & High & 3 & 20 \\
\hline & Normal & 12 & 80 \\
\hline \multirow[t]{2}{*}{ ALP } & High & 9 & 64.3 \\
\hline & Normal & 5 & 35.7 \\
\hline
\end{tabular}

\section{Discussion}

This study is the first COVID 19 report from Ethiopia. The study describes the demographic, clinical characteristics and treatment outcome of the first 33 cases admitted to Ekka-Kotebe COVID 19 treatment center. Similar to reports from other countries outside China, this study showed that most of the cases in this study either arrived from abroad with the disease $73 \%(n=24)$, or had contact with a person diagnosed to have COVID 19 (9).

Similar to reports from Europe and China, males are more likely to develop the infection (7). The clinical profile of patients in this report range from mild symptom of upper respiratory infection to symptoms of organ damage. The clinical manifestation and disease severity at the time of admission in the literatures vary from country to country. Where cases are identified by community screening, most of the cases are 
either pre symptomatic or mild form. In countries where large number of people are infected in a short period of time due to delay in introduction of public health preventive measures, screening and diagnosis of COVID is made mostly on symptomatic cases visiting health care facilities. In these areas, patients often times present late after the initial symptom at stage of moderate to severe disease and those with no symptom or mild diseases may not turn to hospitals (11). The reason for more mild cases in this report may be because most of our cases are diagnosed by screening from quarantine where people coming from abroad or those with contact history are kept for two weeks. Like reports from Asia and Europe, the most frequent clinical symptom in our cases is cough, followed by headache and fever. Rare COVID 19 clinical symptoms reported in literatures, like loss of taste and/or smell sensations were reported in four cases in this study (8-11). This indicate the need to look for very rare symptoms and symptoms not yet reported in COVID 19 confirmed cases, in order to increase the accuracy of clinical diagnostic criteria in settings where testing facility is limited.

Even though in this study nearly half of the cases who had organ function tests had abnormal renal and liver function test result, in all except three it resolved completely, showing that laboratory evidence of organ damage alone may not be strong predictor of mortality.

All cases received Chloroquine sulphate, Azithromycin oral treatment, paracetamol for pain and fever. Oxygen therapy by face mask when oxygen saturation drops below $90 \%$ and by mechanical ventilator when unable to maintain saturation with low flow oxygen treatment was available for the cases in the center. No antiviral medication, convalescent plasma or any traditional medicine was administered for any of the cases included in this report.

Three patients died in the ICU while being on mechanical ventilator.

The first death was to a 60 years old known diabetic female patient on oral hypoglycemic agent, who had recent travel to France, diagnosed with COVID five days after arrival to Ethiopia, transferred to ICU on second day of admission and was on mechanical ventilator for 5 days before death. Possible cause of death was severe hypoxia secondary to ARDS.

The second death was to a 65 years old hypertensive, male who did not have travel or contact history, diagnosed with COVID 19 while in non COVID hospital for respiratory problem, admitted to Ekka-Kotebe treatment center, transferred to ICU on second day of admission and was on mechanical ventilator for two days before death. Possible cause of death being severe hypoxia.

The third death was to a 65 years old, known diabetic female, who did not have contact or travel history, diagnosed with COVID while being treated in ICU of a non COVID hospital, transferred and admitted to Ekka-kotebe COVID treatment center ICU with the diagnosis of critical COVID 19 and was on mechanical ventilator for three days before death. Possible cause of death is multiple organ damage, ARDS.

\section{Conclusion}


Most of our patients in this report are younger than 40 years with male predominance and few have comorbidities. The deaths were 60 years and above. Except three, all cases in this report were either imported or had contacts with confirmed cases. The clinical distribution (mild, moderate, severe and critical) was as it is observed in most other countries. Cough was the commonest symptom followed by headache and fever. As it is in the early stage of the pandemic in Ethiopia, further observation of the new cases in the future will reveal correct sociodemographic and clinical profile of COVID 19 in Ethiopia.

Ekka-Kotebe COVID 19 treatment center has limitation in providing portable chest x-ray for the critically ill patients. More lung pathologies could have been identified if CT scan was accessible in the center.

\section{Abbreviations}

ALP

Alkaline Phosphatase

ALT

Alanine Transferase

AST

Aspartate Transferase

ARDS

Acute Respiratory Distress Syndrome

COPD

Chronic Obstructive Pulmonary Disease

COVID 19

Corona Virus Disease 2019

CT

Computerized Tomography

$\mathrm{GI}$

Gastro Intestinal

ICU

Intensive Care Unit

RT PCR

Reverse Transcription Polymerase Chain Reaction

SARS CoV 2

Severe Acute Respiratory Syndrome Corona Virus 2

WHO

World Health Organization

\section{Declarations}

Ethics approval and Consent: Saint Paul's Hospital Millennium Medical College Institutional Review Board approved the study and written consent was obtained from the cases during chart review and 
interview.

Consent for publication: consent to publish this study was obtained from participants before they were discharged from the hospital using written consent form.

Availability of data and materials: The data collected to generate the result in this study are available from the corresponding author up on request.

Competing interest: The authors declare that they have no competing interest.

Funding: There was no funding involved in this study

\section{Authors' contribution:}

ST, AA, AW, RA, MT, WA design and conception of this study and wrote the final manuscript

MS, WW, BR, MW, SY were involved in data cleaning, data entry and analysis

$A B, Y G, H A, A B, G D, B T$ collected data from the chart and patient interview for incomplete data.

YS, AG, AA, NT were involved in reference search and edited the manuscript

All authors have read and approved the final manuscript.

Acknowledgement: We would like to extend our gratitude to Ekka-Kotebe COVID 19 treatment center for facilitating data collection, Ethiopian Federal Ministry of Health for facilitating the platform for this report, Ethiopian public Health Institute for coordinating the COVID treatment under the Emergency Operation Center(EOC), and all health care workers involved in the care of COVID 19 patients at Ekka Kotebe Hospital.

\section{References}

1. WHO. Novel Coronavirus-China. https://www.who.int/csr/don/12-january-2020-novel-coronaviruschina/en/.

2. $10.1101 / 2020.02 .07 .937863$

Gorbalenya AE, Baker SC, Baric RS, et al. Severe acute respiratory syndrome-related coronavirus: the species and its viruses - a statement of the Coronavirus Study Group. bioRxiv. 2020; (published online Feb 11.) (preprint). DOI: 10.1101/2020.02.07.937863 ).

3. Report of WHO-China Joint Mission on Coronavirus Disease. 2019, Feb 16-24/2020.

4. WHO. Virtual press conference on COVID-19-11 March 2020. March 11. 2020. https://www.who.int/docs/default-source/coronaviruse/transcripts/who-audio- emergenciescoronavirus-press-conference-full-and-final-11 mar2020.pdf?sfvrsn = cb432bb3_2. 
5. Bedford J, Enria D, Giesecke J, et al. COVID-19: towards controlling of a pandemic. Lancet 2020; published online March 17. https://doi.org/ 10.1016/S0140-6736(20)30673-5.

6. WHO. COVID 19 situation report-97, April 26, 2020.

7. Adhikari, et al. Epidemiology, causes, clinical manifestation and diagnosis, prevention and control of coronavirus disease (COVID-19) during the early outbreak period: a scoping review. Infectious Diseases of Poverty. 2020;9:29.

8. https://doi.org/10.1186/s40249-020-00646-x.

9. Guan W, Ni Z, Hu Y, et al. Clinical characteristics of coronavirus disease 2019 in China. N Engl J Med. 2020. doi:10.1056/NEJMoa2002032].

10. Nitesh, Gupta, et al. Clinical and epidemiologic profile of the initial COVID-19 patients at a tertiary care centre in India. Monaldi Archives for Chest Disease 2020; 90:1294] P 193 - 96.

11. Andrea Saglietto FD'Ascenzo, Zoccai GB. Gaetano Maria De Ferrari COVID-19 in Europe: the Italian lesson The Lancet 2020. Published Online March 23, 2020 https://doi.org/10.1016/ S01406736(20)30690-5.

12. Giacamo Grasselli MD, Alberto Zangrillo MD, Alberto Zanella MD, et al, Baseline Characteristics and Outcomes of 1591 Patients Infected With SARS-CoV 2 Admitted to ICUs of the Lombardy region, Italy, JAMA, Published online April 6,2020. 